\title{
HUBUNGAN BEBAN KERJA DENGAN KEPATUHAN PERAWAT \\ DALAM PENERAPAN SURGICAL SAFETY CHECKLIST \\ DI KAMAR OPERASI RUMAH SAKITAWAL \\ BROS BATAM TAHUN 2020
}

\author{
MASTER SAMSON RIO \\ SISKA NATALIA \\ YULIANTI WULANDARI \\ STIKes Awal Bros Batam
}

Email : mastersamsonriopanjaitan@gmail.com,Wwoelan@gmail.com,

\begin{abstract}
Impact Workload that is too excessive will result in adverse effects, which will cause physical and mental fatigue and emotional reactions such as headaches, digestive disorders, and irritability. While the workload is too little where the work happens because reduced motion will lead to boredom. Boredom in the work done or too little work results in a lack of attention to work that can potentially endanger workers and conversely the many burdens in work make other jobs neglected and forget some things to do because of high workload (Ma-nuaba , in Prihatini, 2017) nurse workload is strongly correlated with the large number of patients who have filled out the form before the surgery, and the length of treatment in the recovery room and the rapid process of dropping patients into the operating room before the patient's recovery from the operating room is complete.The study aims to determine the relationship between workload and nurse compliance. Methods The study is cross sectional. Instrument of research is using the instrument, sample research is 30 nurses. The results of this study get more than $70 \%$ of the workload and compliance of nurses $67 \%$ in this case the results of the Chi-square test conducted in there can be a significant relationship between workload with nurse compliance with a significant value of $\mathrm{p}<0.05$ i.e. $=0,004$.
\end{abstract}

Keywords: workload, compliance nurse

\section{PENDAHULUAN}

Rumah sakit adalah "institusi
pelayanan kesehatan yang
menyelenggarakan pelayanan kesehatan
perorangan secara paripurna yang
menyediakan rawat inap, rawat jalan
dan gawat darurat. Salah satu fasilitas
pelayanan di rumah sakit adalah
pelayanan pembedahan/operasi. Rumah
sakit mengutamakan keselamatan
pasien untuk meningkatkan mutu
pelayanannya dan mendapatkan
kepercayaan serta kepuasan masyarakat
terkait dengan pelayanan yang telah
diberikan. Pemerintah mewajibkan
program keselamatan pasien di setiap
rumah sakit dan akan dievaluasi
melalui akreditasi oleh Komisi

Akreditasi Rumah Sakit" (T
Bramantoro, 2017).
"Keselamatan pasien dan
kualitas pelayanan pasien adalah hal
yang sangat penting dari
penyampaian layanan kesehatan.
Untuk setiap pasien, anggota keluarga
dan profesional kesehatan,
keselamatan sangat penting untuk
penegakkan diagnosa, tindakan
kesehatan dan perawatan. Dokter,
perawat dan semua orang yang
bekerja di sistem kesehatan
berkomitmen untuk merawat dan
membantu pasien dan memiliki
keunggulan dalam penyedia layanan
kesehatan untuk semua orang yang
membutuhkan. Namun sistem
kesehatan di seluruh dunia,


menghadapi tantangan dalam menangani praktik yang tidak aman, profesional layanan kesehatan yang tidak kompeten, tata pemerintahan yang buruk dalam pemberian layanan kesehatan, kesalahan dalam diagnosis dan perawatan dan ketidakpatuhan terhadap standar keselamatan pasien" (D, Madden 2018).

Keselamatan pasien rumah sakit adalah "suatu sistem dimana rumah sakit membuat asuhan pasien lebih aman yang meliputi asesmen risiko, identifikasi dan pengelolaan hal yang berhubungan dengan risiko pasien, pelaporan dan analisis insiden, kemampuan belajar dari insiden dan tindak lanjutnya serta implementasi solusi untuk meminimalkan timbulnya risiko dan mencegah terjadinya cedera yang disebabkan oleh kesalahan akibat melaksanakan suatu tindakan atau tidak mengambil tindakan yang seharusnya diambil" (Biyang, fanny. 2008) Permasalahan patient safety terus diteliti dan dikembangkan oleh berbagai pihak penyedia layanan kesehatan. Berdasarkan Hasil penelitian Diah Pratiwi tentang Faktor-faktor yang berhubungan dengan penerapan patient safety pada perawat menyatakan "ada hubungan antara pendidikan, pelatihan, pengetahuan dan motivasi dengan penerapan patient safety di instalasi rawat inap Rumah Sakit Umum Pancaran Kasih GMIM Manado" (Diah Pratiwi Renoningsih, n.d. 2016) .

Salah satu pelayanan yang diberikan oleh rumah sakit adalah pelayanan pembedahan/operasi. Pemberian pelayanan pembedahan hal yang harus penting dan mutlak diperhatikan adalah keselamatan pasien. World Health Organization (WHO) menjelaskan bahwa "surgical safety checklist kamar bedah digunakan melalui 3 tahap, masing-masing sesuai dengan alur waktunya yaitu saat sebelum induksi anestesi (Sign In), sebelum dilakukan insisi (Time Out) dan sebelum mengeluarkan pasien dari kamar operasi (Sign Out). merupakan alat komunikasi praktis dan sederhana dalam memastikan keselamatan pasien dalam tahap preoperatif, intraoperatif dan paska operatif" (WHO,2008). Secara Umum dalam pelaksanaan pengisian Surgical Safety Checklist (SSC) ada beberapa kendala sehingga tidak bisa sepenuhnya dilaksanakan dengan baik salah satunya adalah faktor beban kerja.

"Beban kerja perawat yang bekerja di rumah sakit berkaitan dengan asuhan keperawatan yang harus diberikan kepada pasien. Menurut Arwani dan Supriyanto" (2006 dikutip dari Minarsih, 2014). Hal-hal yang menjadi pertimbangan dalam beban kerja perawat adalah "jumlah pasien yang dirawat, kondisi atau tingkat ketergantungan pasien, dan jumlah ratarata hari perawatan pasien, aktivitas keperawatan langsung, tidak langsung dan pendidikan kesehatan serta rata-rata waktunya, dan frekuensi tindakan yang dibutuhkan pasien.Bila banyaknya tugas tidak sebanding dengan kemampuan baik fisik maupun keahlian dan waktu yang tersedia maka akan menjadi sumber kelelahan" (Ilyas, 2014). Dampak Beban kerja yang terlalu berlebihan akan mengakibatkan dampak yang tidak baik,yaitu akan menimbulkan kelelahan baik secara fisik maupun mental dan reaksi-reaksi emosional seperti sakit kepala,gangguan pencernaan, dan mudah marah. Sedangkan beban kerja yang terlalu sedikit di mana pekerjaan yang terjadi karena pengurangan gerak akan menim-bulkan kebosanan. "Rasa bosan dalam kerja yang dilakukan atau pekerjaan yang terlalu sedikit mengakibatkan kurangnya perhatian pada pekerjaan sehingga secara potensial membahayakan pekerja dan sebaliknya banyaknya beban dalam pekerjan membuat pekerjaan lain terbengkali dan lupa akan beberapa hal 
yang harus di lakukan karena beban yang kerja yang tinggi" (Ma-nuaba, dalam Prihatini, 2017).

Dalam hal ini Beban kerja banyak dialami oleh perawat "dimana dapat dilihat dari dimensi seluruh kegiatan atau aktivitas yang dilakukan oleh seorang perawat selama bertugas di suatu unit pelayanan keperawatan" (Nursalam, 2012).

Dengan demikian beban kerja yang harus ditanggung oleh perawat tergantung pada tugas perawat dalam suatu unit pelayanan keperawatan. Beban kerja yang berlebihanakan berpengaruh terhadap produktifitas tenaga kesehatan dan tentu saja berpengaruh terhadap produktifitas rumah sakit itu sendiri.

"Beban kerja perawat adalah seluruh kegiatan atau aktivitas yang dilakukan oleh seorang perawat selama bertugas di suatu unit pelayanan keperawatan" (Marquis dan Huston, 2004 dalam I GST A.A Putri Mastini 2013). Penelitian sebelumnya dilakukan oleh Luciana Bjorklund de lima dalam Nursing Workload in the postanesthesia care unit Hospital de Clinicas de Porto Alegre, RS, Brazil tahun 2011. Didapatkan hasil 50\% beban kerja perawat dipengaruhi oleh lama perawatan di ruang postanesthesia care unit/recovery room dan lamanya operasi.

Penelitian sebelumnya oleh I GST A.A Putri Mastini dalam tesis Hubungan Pengetahuan,Sikap dan Beban kerja dengan Kelengkapan Pendokumentasian Asuhan Keperawatan Irna di RSUP Sanglah denpasar tahun 2013. Didapatkan hasil 95,8\% beban kerja sedang kelengkapan pendokumentasian tidak sesuai, didapatkan hasil penelitian ada hubungan beban kerja dengan kelengkapan pendokumentasian asuhan keperawatan. Berdasarkan latar belakang tersebut dan didukung oleh penelitian terdahulu, maka peneliti tertarik untuk melakukan penelitian lebih lanjut tentang Hubungan Beban Kerja dengan Kepatuhan Pengisian Surgical Patient Safety Checklist pada Perawat di Instalasi Bedah Sentral RS St. Elisabeth Semarang

Menurut penelitian Karlina tentang evaluasi kepatuhan tim bedah dalam penerapan surgical safety cheklist WHO pada operasi bedah mayor di instalasi bedah sentral PKU Muhammadiyah Bantul menyatakan "pengisian surgical safety checklist baik sign in, time out, maupun sign out di Instalasi Bedah Sentral RS PKU Muhammadiyah Bantul termasuk dalam kriteria kurang patuh" (Karlina, 2018) Hal ini sejalan dengan hasil studi pendahuluan yang saya lakukan di ruang operasi Rumah Sakit Awal Bros Batam pada tanggal 8 Desember 2019, saya sebagai peneliti mendata secara langsung total perawat Ruangan operasi sebannyak 34 orang perawat dimana 5 diantara mengatakan beban kerja di ruangan operasi tinggi karena banyaknya jumlah pasien yang setiap harinya akan di operasi tidak sebanding dengan proses pengisian surgical safety checklist baik sign in, time out, maupun sign out, yang harus di isi . belum selesai satu pasien dating lagi pasien selanjutnya, sehingga pengisian surgical safety checklist kadang terbengkali dan peneliti berasumsi hal ini termasuk kriteria ketidakpatuhan perawat, dalam hal ini Berkesimpulan beban kerja perawat berkorelasi kuat dengan jumlah pasien yang banyak dengan proses pengisian form sebelum operasi di lakukan, dan lama perawatan di ruang pemulihan dan cepatnya proses penurunan pasien ke ruang operasi sebelum pemulihan pasien dari kamar operasi selesai. Dalam hal ini peneliti tertarik untuk meneliti' Hubungan Beban Kerja Dengan Kepatuhan Perawat Dalam Penerapan Surgical Safety Checklist Di Kamar Operasi 
Rumah Sakit awal Bros Batam Tahun

\section{0}

\section{METODOLOGI PENELITIAN}

Desain penelitian yang dilakukan oleh peneliti merupakan penelitian kuantitatif dengan pendekatan cross sectional. Sampel yang diambil 30 orang perawat kamar operasi dengan tehknik total sampling. Penelitian ini menggunakan analisis chi shi square untuk analisis bivariat.

\section{HASIL DAN PEMBAHASAN}

\section{A. Karakteristik Responden}

Tabel 4.1

Distribusi Responden Berdasarkan Jenis Kelamin, Usia, Pekerjaan, Masa Kerja, Pendidikan

\begin{tabular}{lcl}
\hline No $\quad$ Variabel & Frekuensi & Presentase \% \\
\hline Jenis & & \\
Kelamin & 17 & 57.0 \\
Laki-laki & 13 & 100 \\
Perempuan & 30 & \\
& & \\
Total & & \\
Usia & & 47 \\
(20-30th) & 14 & 40 \\
(30-40) & 12 & 13 \\
(40-50th) & 4 & 100 \\
Total & 30 & \\
& & \\
Masa Kerja & & \\
$<3$ tahun & 10 & 33 \\
3 tahun s/d 5 & 11 & 37 \\
tahun & 9 & 30 \\
$>5$ tahun & 30 & 100 \\
Total & & \\
& & \\
Pendidikan & & \\
D3 & 21 & 70 \\
Keperawatan & 2 & 7 \\
S & 6 & 20 \\
Keperawatan & 1 & 3 \\
Ners & 30 & 100 \\
S2 & & \\
Total & & \\
& &
\end{tabular}

Sumber : Data Primer, 2020

Tabel diatas terlihat frekuensi jenis kelamin di dominasi oleh laki-laki yaitu 17 responden ( 57.0\%) frekuensi umur di dominasi 20-30 tahun yaitu 14 responden (47\%) frekuensi masa kerja di dominasi 3-5 tahun 21 responden $37.0 \%$, frekuensi Pendidikan di dominasi D3 Keperawatan 21 responden atau $45.7 \%$.

Tabel 4.2

Distribusi Frekuensi Dan Persentase Beban Kerja Di Kamar Operasi Awal Bros Batam Tahun 2020

\begin{tabular}{ccc} 
Beban kerja & Frekuensi & Persentase $(\%)$ \\
\hline Tinggi & 21 & 70.0 \\
Rendah & 9 & 30.0 \\
Total & 30 & 100
\end{tabular}

Dari Tabel 4.2 Di atas beban kerja di kamar operasi tinggi atau $70 \%$ menunjukan bahwa responden yang merasa beban kerja sedang lebih banyak di banding dengan beban kerja tinggi dan beban kerja rendah Hasil penelitian juga sejalan yang di lakukan oleh Martini (2017), bahwa "beban kerja perawat dirumah sakit ratarata 66,8 \%. Beban kerja perawat di kamar operasi adalah di mana keadaan di mana perawat di hadapkan pada tugas atau pekerjaan yang harus di selesaikan salama bertugas". 
Tabel 4.3

Distribusi Frekuensi dan Persentase kepatuhan perawat Penerapan Surgical Safety Checklist Di Kamar Operasi Rumah Sakitawal Bros Batam Tahun 2020

\begin{tabular}{|c|c|c|}
\hline $\begin{array}{c}\text { Kepatuhan } \\
\text { perawat }\end{array}$ & Frekuensi & $\begin{array}{c}\text { Persentase } \\
(\mathbf{\%})\end{array}$ \\
\hline Patuh & 10 & 33.0 \\
\hline $\begin{array}{c}\text { Tidak } \\
\text { patuh }\end{array}$ & 20 & 67.0 \\
\hline Total & 30 & $100 \%$ \\
\hline
\end{tabular}

hubungan yang signifikan antara beban kerja dengan kepatuhan perawat Penerapan Surgical Safety Checklist Di Kamar Operasi Rumah Sakit awal Bros Batam Tahun 2019. Hal ini sejalan dengan penelitian yang dilakukan oleh Retyaningsih, bambang Edi, Warsito (2013), penelitian menunjukkan penerapan ceklis surgical tidak baik $(84,9 \%)$ Hal ini juga sesuai dengan penelitian yang dilakukan oleh I Gusti A.A Putri Mastini (2013) di RSUP. Sanglah Denpasar adanya hubungan antara beban kerja dengan penerapan ceklist surgical dengan nilai Pvalue $=0,004<0,05$.

\section{Hasil Univariat Gambaran beban kerja}

Berdasarkan data hasil penelitian melalui lembar kuesioner, Hasil penelitian menunjukkan beban kerja pada perawat di kamar operasi awal bros batam yaitu Tinggi $(70 \%)$ Analisa beban kerja objektif merupakan kegiatan produktifitas tenaga perawat yang dinyatakan dalam bentuk proposi waktu kerja yang dikelompokkan menjadi empat yaitu kegiatan keperawatan langsung, kegiatan keperawatan tidak langsung, kegiatan pribadi dan kegiatan non produktif. Beban kerja penting diketahui sebagai dasar untuk mengetahui kapasitas kerja perawat agar terdapat keseimbangan anatara tenaga keperawatan dengan beban kerja (Namaganda et al. 2015).

beberapa hal yang sering menjadi alasan para petugas antara lain, banyak kegiatankegiatan di luar tanggung jawab perawat menjadi beban yang di kerjakan oleh profesi keperawatan. Menurut wawancara dengan 5 orang perawat, "semuanya tidak dapat membuat dokumentasi pisuhan keperawatan. Perawat lebih banyak mengerjakan pekerjaan koordinasi dan limpahan wewenang. Beban kerja perawat tidak hanya merawat pasien saja yaitu kegiatan langsung, tetapi juga kegiatan tidak langsung yang tak 0 ,dolah penting yaitu seperti melengkapi dan melaksanakan dokumentasi asuhan keperawatan dan catatan medik yang terperinci" (Mastini, 2013). "Beban kerja penting di ketahui sebagai dasar untuk mengetahui kapasitas kerja perawat agar terdapat keseimbangan antara tenaga perawat dan beban kerja" (Hendiati, Soemantri, Yudianto, 2012).

Hasil Uji statistic chi square di atas di dapatkan $\rho$ 0,004 yang berarti terdapat
"Beban kerja perawat yang bekerja di rumah sakit berkaitan dengan asuhan 
keperawatan yang harus diberikan kepada pasien". Menurut Arwani dan Supriyanto (2006 dikutip dari Minarsih, 2011) "hal-hal yang menjadi pertimbangan dalam beban kerja perawat adalah jumlah pasien yang dirawat, kondisi atau tingkat ketergantungan pasien, rata-rata hari perawatan pasien, aktivitas keperawatan langsung, tidak langsung dan pendidikan kesehatan serta rata-rata waktunya, dan frekuensi tindakan yang dibutuhkan pasien. Bila banyaknya tugas tidak sebanding dengan kemampuan baik fisik maupun keahlian dan waktu yang tersedia maka akan menjadi sumber stres" (Ilyas, 2001). Menurut Munandar (2008) "akibat dari meningkatnya beban kerja adalah timbulnya emosi perawat yang tidak sesuai dengan yang diharapkan pasien. Unsur yang menimbulkan beban berlebih ialah kondisi kerja. Kondisi kerja meliputi variabel lingkungan kerja fisik seperti suhu udara, pencahayaan, kebisingan".

Penelitian ini didukung oleh jurnal penelitian yang dilakukan oleh (Julia et al. 2014) yang berjudul Analisa Kebutuhan Tenaga Perawat Berdasarkan Beban Kerja dengan Menggunakan Metode Workload Indicator Staff Need(WISN) dan Work Sampling dengan hasil penelitian "pengamatan Work Sampling menunjukkan bahwa kedua perawat telah bekerja dengan baik karena rata-rata waktu produktifnya 93\%(beban kerja katagori tinggi). Hasil perhitungan dengan metode Workload Indicator Staff Need (WISN) diketahui kebutuhan perawat sebesar 2 orang, sedangkan hasil analisis menunjukkan perlunya penambahan 1 orang tenaga perawatdi poli, dengan Rasio WISN menunjukkan 0.7 , sehingga dikategorikan kurang staff, sehingga perlunya mengetahui jumlah tenaga perawat berdasarkan beban kerja karena dapat mengetahui jumlah perawat dan berapa besar beban kerja yang dialami oleh tenaga perawat tersebut agar tidak berdampak terhadap keselamatan pasien". Pernyataan tersebut didukung oleh jurnal (Ross et al. 2018) yang berjudul Safety Culture and Invisible Nursing Workload, dengan hasil penelitian yaitu dengan mengidentifikasibeban kerja perawat didapatkan dampakterhadap keselamatanpasien sehingga, penelitian tersebut berfokus pada beban kerja perawat dan keselamatan pasien,karena beban kerja yang tinggi dapat meningkatkan risiko terhadap keselamatan pasien. Adapaun efek negatifjika beban kerja tinggiuntuk pasien termasuk kejadian buruk dan kegagalan untuk penyelamatan dan dampak negative bagi perawat meliputi rendahnya kepuasan kerja, kelelahan emosionaldan setres kerja.

Maharja (2015) menyatakan bahwa "perawat memiliki tuntutan pekerjaan yang tinggi, khususnya pada perawat yang bertugas di Instalasi Rawat Inap. Hal ini disebabkan karena seluruh asuhan keperawatan dilakukan 24 jam selama 7 hari sehingga menambah tanggung jawab asuhan keperawatan disbanding perawat pada instalasi lainnya. Tuntutan pekerjaan yang tinggi tersebut dapat mengganggu kesehatan perawat". Robbins (2010) menyatakan bahwa "positif negatifnya beban kerja merupakan masalah persepsi. Persepsi didefinisikan sebagai suatu proses dimana individu mengorganisasikan dan menafsirkan kesan indera mereka agar memberi makna kepada lingkungan mereka. Hal ini dikarenakan persepsi terhadap beban kerja merupakan hal yang erat hubungannya dengan suatu pekerjaan, dimana individu memberikan penilaian mengenai sejumlah tuntutan tugas atau kegiatan yang membutuhkan aktivitas mental dan fisik yang harus ia selesaikan dalam waktu tertentu, apakah memiliki dampak positif atau negatif terhadap pekerjaannya".

Dalam hal ini ada beberapa faktor yang mempengaruhi beban kerja salah satunya stress kerja , beban kerja , dan faktor lainnya dlam hal ini hasil penelitian terkait kepatuhan Perawat Hasil penelitian yang dilakukan Luciana Bjorklund de lima (2011), Didapatkan hasil 50\% beban kerja perawat dipengaruhi oleh lama perawatan di ruang post-anesthesia care unit/recovery room dan lamanya operasi sehingga kesimpulan dari penelitian menunjukkan beban kerja perawat berkorelasi kuat dengan lama perawatan di ruang pemulihan.

Dari hasil penelitian yang dilakukan didaptkan adanya gambaran Beban Kerja Di Kamar Operasi Rumah Sakitawal Bros Batam Tahun 2019. Hasil penelitian menunjukkan beban kerja pada perawat di kamar operasi awal bros batam yaitu Tinggi $(70 \%)$

\section{Gambaran kepatuhan perawat}

Berdasarkan data hasil penelitian melalui lembar kuesioner, Hasil penelitian menunjukkan tidak patuh pada perawat dalam penerapan ceklist surgical di kamar operasi awal bros batam yaitu Tinggi (66\%) "Persiapan 
pre operasi penting sekali untuk memperkecil risiko operasi, karena hasil akhir suatu pembedahan sangat tergantung pada pengkajian fase ini. Hal ini disebabkan karena pada fase ini merupakan awalan yang menjadi tolok ukur kesuksesan pada tahap-tahapan selanjutnya dan untuk menjamin keselamatan pasien intra operatif. Seseorang yang memiliki motivasi tinggi maka tingkat kepatuhannya akan meningkat dan jika motivasian rendah maka tingkat kepatuhannya semakin rendah. Pada fase sign in, tim operasi melakukan memeriksa kesiapan pasien, informed consent, site marking, persediaan darah, waktu makan dan minum terakhir, risiko aspirasi, pelepasan perhiasan, tambahan informasi dan jam verifikasi. Fase sign in dimaksudkan untuk memastikan kesiapan pasien dan peralatan yang digunakan untuk melakukan operasi. Tindakan tim operasi sesuai dengan prosedur operasi sign in yang ditetapkan oleh WHO”.

Menurut WHO 2008 menyebutkan bahwa "fase sign 64 in adalah fase sebelum induksi anestesi dimana koordinator secara verbal memeriksa apakah identitas pasien telah di konfirmasi, prosedur dan sisi operasi sudah benar, sisi yang akan di operasi telah ditandai, persetujuan untuk operasi telah diberikan, pulse oximeter pada pasien berfungsi. Koordinator dengan profesional anestesi mengkonfirmasi risiko pasien apakah pasien ada risiko kehilangan darah, kesulitan jalan nafas, atau reaksi alergi".

Dari hasil penelitian terkait tentang kepatuhan tim operasi dalam penerapan surgical patient safety pada operasi di salah satu rumah sakit Indonesia dapat disimpulkan bahwa tim operasi tersebut tidak patuh dalam menerapkan surgical patient safety fase sign in yang terdiri dari mengkonfimasi identitas pasien, konfirmasi lokasi insisi, pengecekan mesin anestesi dan obat-obatan, konfirmasi apakah pasien mempunyai riwayat alergi, konfirmasi apakah pasien ada kesulitan bernafas/resiko aspirasi dan penggunaan alat bantu nafas, konfirmasi resiko kehilangan darah dan konfimasi akses intravena/rencana terapi cairan.
Menurut Tamsuri (2017) pada fase sign in merupakan "awalan yang menjadi tolok ukur kesuksesan pada tahaptahapan selanjutnya dan untuk menjamin keselamatan pasien intra operatif. Ketidakpatuhan tim operasi untuk menerapkan sign in dapat dipengaruhi oleh kondisi tim operasi yang capek karena banyaknya operasi yang harus ditangani. Kondisi tersebut mempengaruhi motivasi tim operasi untuk mengisi lembar sign in dengan lengkap. Menurut peneliti salah satu faktor yang mempengaruhi kepatuhan adalah motivasi. Motivasi pada dasarnya merupakan interaksi seseorang dengan situasi tertentu yang dihadapinya, jadi motivasi adalah suatu alasan seseorang untuk bertindak dalam rangka memenuhi kebutuhan hidupnya".

Dari hasil penelitian yang dilakukan didapatkan adanya gambaran kepatuhan Di Kamar Operasi Rumah Sakitawal Bros Batam Tahun 2020. hasil penelitian melalui lembar kuesioner, Hasil penelitian menunjukkan tidak patuh pada perawat dalam penerapan ceklist surgical di kamar operasi awal bros batam yaitu Tinggi $(66 \%)$

\section{Hasil Uji Bivariat}

Hubungan Beban Kerja Dengan Kepatuhan Perawat Dalam Penerapan Surgical Safety Checklist Di Kamar Operasi Rumah Sakitawal Bros Batam Tahun 2020

Penelitian yang dilakukan mengenai beban kerja memiliki hasil yang signifikan di dapatkan nilai $\rho$ 0,004 yang sama dari hasil penelitian yang terdahulu Luciana Bjorklund de lima dalam Nursing Workland in the postanesthesia care unit Hospital de Clinicas de Porto Alerge, RS, Brazil tahun 2011. bahwa faktor beban kerja perawat dapat mempengaruhi dalam kepatuhan pendokumentasian. Didapatkan hasil 50\% beban kerja perawat dipengaruhi oleh lama perawatan di ruang post-anesthesia care unit/recovery room dan lamanya operasi sehingga kesimpulan dari penelitian menunjukkan beban kerja perawat berkorelasi kuat dengan lama perawatan di ruang pemulihan

Dalam hal ini ada hubungan yang signifikan antara Beban Kerja dengan kepatuhan perawat pada perawat jika dilihat dari tabel nilai siginifikan $\rho$ (0.004). Dan 
juga di buktikan dari penelitian terkait yang ada dalam penelitian Luciana Bjorklund de lima dalam Nursing Workland in the postanesthesia care unit Hospital de Clinicas de Porto Alerge, RS, Brazil tahun 2011. Banyak faktor yang mempengaruhi kepatuhan itu sendiri dalam hal ini mungkin saja ada kaitannya dengan pendidikan dimana pendidikan dominasi oleh D3 keperawatan . Penelitian yang dilakukan mengenai beban kerja memiliki hasil yang sama dari hasil penelitian yang terdahulu, bahwa faktor beban kerja perawat dapat mempengaruhi dalam kepatuhan pendokumentasian. Luciana Bjorklund de lima dalam Nursing Workland in the post- anesthesia care unit Hospital de Clinicas de Porto Alerge, RS, Brazil tahun 2011. Didapatkan hasil 50\% beban kerja perawat dipengaruhi oleh lama perawatan di ruang post-anesthesia care unit/recovery room dan lamanya operasi sehingga kesimpulan dari penelitian menunjukkan beban kerja perawat berkorelasi kuat dengan lama perawatan di ruang pemulihan. Penelitian I GST A.A Putri Mastini dalam tesis Hubungan Pengetahuan,Sikap dan Beban kerja dengan Kelengkapan Pendokumentasian Asuhan Keperawatan Irna di RSUP Sanglah denpasar tahun 2013. Didapatkan hasil 95,8\% beban kerja sedang kelengkapan pendokumentasian tidak sesuai, didapatkan hasil penelitian ada hubungan beban kerja dengan kelengkapan pendokumentasian asuhan keperawatan. Ryny Silvana dalam penelitian Hubungan Beban Kerja dengan Pendokumentasian Asuhan Keperawatan di Instalasi Gawat Darurat Medik RSUP. Prof. DR. S.D.Kandaouw Manado tahun 2014. didapatkan hasil 85,7\% dengan beban kerja berat tidak melakukan pendokumentasian keperawatan secara lengkap, didapatkan hasil penelitian ada hubungan beban kerja dengan pendokumentasian asuhan keperawatan. Penelitian Efa Trisna tentang Hubungan Persepsi Tim Bedah dengan Kepatuhan Penerapan Surgical Patient Safety pada Pasien Operasi Bedah Rumah Sakit Umum Daerah Mayjend HM.Ryacudu Kotabumi Kabupaten Lampung Utara tahun 2016 yang terdapat hubungan yang bermakna antara persepsi tim bedah tentang Surgical patient safety dengan kepatuhan penerapan Surgical Patient Safety, dalam kategori tidak patuh $40 \%$.

Menurut penelitian Efa Trisna tentang hubungan persepsi tim bedah dengan kepatuhan penerapan Surgical Patient Safety pada pasien operasi bedah rumah sakit umum daerah
Mayjend HM. Ryucudu "didapatkan hasil ada hubungan bermakna antara persepsi tim bedah dengan kepatuhan penerapan Surgical Patient Safety" (Trisna, 2016) .

Perawat merupakan "salah satu profesi di rumah sakit yang memiliki peran penting dalam penyelenggaraan pelayanan kesehatan. Oleh karena itu, rumah sakit tempat perawat bekerja senantiasa melakukan berbagai usaha yang bertujuan untuk meningkatkan kualitas profesionalisme perawat. Keperawatan merupakan bagian integral dari sistem pelayanan kesehatan dan merupakan salah satu faktor yang menentukan mutu pelayanan kesehatan. Untuk itu perlu diperhatikan kinerja perawat dalam melaksanakan tugas dan fungsinya dalam memberikan pelayanan kesehatan kepada pasien. Pelayanan yang diberikan oleh perawat masih sering dikeluhkan oleh masyarakat. Sorotan terhadap kinerja perawat merupakan masalah yang harus segera ditanggulangi, sebab pelayanan keperawatan menentukan mutu pelayanan rumah sakit. Kinerja yang jelek akan berdampak terhadap rendahnya pelayanan, pasien merasa kurang nyaman dan tidak puas. Kinerja dalam hal ini erat kaitannya dengan seberapa besar beban kerja, stres kerja dan motivasi kerja perawat dalam memberikan pelayanan kesehatan. Semakin rendah beban kerja dan stres kerja perawat semakin baik kinerjanya. Semakin besar motivasi kerja perawat semakin baik kinerjanya".

Selain masalah beban kerja, faktor stres kerja juga memegang peranan penting dalam upaya meningkatkan kinerja perawat. "Bila tidak ada stres, tantangan kerja juga tidak ada. Sebaliknya bila stres terlalu tinggi, kinerja akan menurun karena stres mengganggu pelaksanaan pekerjaan. Stres kerja menyebabkan perawat kehilangan kemampuan untuk mengendalikannya. Akibat yang paling ekstrim adalah kinerja menjadi rendah, perawat menjadi kehilangan semangat dalam bekerja, putus asa, keluar atau menolak bekerja untuk menghindari stres".

Dalam hal ini penelitian ini juga sejalan dengan penelitian yang dilakukan peneliti 
tentang Hubungan Beban Kerja Dengan Kepatuhan Perawat Dalam Penerapan Surgical Safety Checklist Di Kamar Operasi Rumah Sakit awal Bros Batam Tahun 2019 dimana hasil penelitian terdapat hubungan yang signifikan di dapatkan nilai $\rho 0,004$, namun dalam hal ini ada beberapa faktor yang mempengaruhi kepatuhan itu sendiri bukan hanya beban kerja . salah satunya motivasi, stress, reward dan lainnya.

\section{Implikasi Penelitian}

Berdasarkan hasil penelitian yang Telah Dilakukan kelengkapan dokumentasi merupakan merupakan salah satu indicator rumah sakit, Karena baik buruknya mutu pelayan yang di berikan kepada pasien dapat di ukur melalui dokumentasi keperawatan yang di buat oleh perawat kelengkapan dokumentasi keperawatan di rs awal bros batam ini masih terbilang baik namun akan tetapi pelu tetap di pertahan dan di tingkatkan kualitas kerjanya. Dalam penelitian ini melihat adanya hubungan yang signifikan terkait kepatuhan perawat itu sendiri

\section{KESIMPULAN}

Berdasarkan hasil penelitian yang dilakukan menyimpulkan sebagai berikut:

1. Lebih dari sebagian responden $(70 \%)$ beban kerja perawat tinggi

2. Lebih dari sebagian responden (67\%) tidak patuh perawat tinggi

3. Adanya Hubungan Beban Kerja Dengan Kepatuhan Perawat Dalam Penerapan Surgical Safety Checklist Di Kamar Operasi Rumah Sakitawal Bros Batam Tahun 2019 Diperolehhasil p.value 0,004 $(<0,005)$

\section{DAFTAR PUSTAKA}

Anugrahini, C., Sahar, J., \& Mustikasari, M. (2010). Kepatuhan Perawat Menerapkan Pedoman Patient Safety Berdasarkan Faktor
Individu dan Organisasi. Jurnal

Keperawatan Indonesia.

https://doi.org/10.7454/jki.v13i3.244

Babayan, R. K. (2013). Re: The effect of the

WHO surgical safety checklist on complication rate and communication.

Journal of Urology.

https://doi.org/10.1016/j.juro.2013.05.043

Bashford, T., Reshamwalla, S., McAuley, J., Allen, N. H., McNatt, Z., \& Gebremedhen, Y. D. (2014). Implementation of the WHO Surgical Safety Checklist in an Ethiopian Referral Hospital. Patient Safety in Surgery. https://doi.org/10.1186/17549493-8-16

Commission, T. J. (2015). National Patient Safety Goals Effective January 1, 2015. Hospital National Patient Safety Goals.

Harus, B. D., \& Sutriningsih, A. (2015). Pengetahuan Perawat tentang Keselamatan Pasien dengan Pelaksanaan Prosedure Keselamatan Pasien Rumah Sakit (KPRS) di Rumah Sakit Panti Waluya Sawahan Malang. Jurnal Ilmiah Ilmu Kesehatan. https://doi.org/10.33366/CR.V3I1.300

Irmawati, N. E., \& Anggorowati, A. (2017). SURGICAL CHEKLIST SEBAGAI UPAYA MENINGKATKAN PATIENT SAFETY. Journal of Health Studies. https://doi.org/10.31101/jhes.184

Mustikawati, I. S. (2003). Etika Penelitian. Metodelogi Penelitian.

Neri, R. A., Lestari, Y., \& Yetti, H. (2018). Analisis Pelaksanaan Sasaran Keselamatan Pasien Di Rawat Inap Rumah Sakit Umum Daerah Padang Pariaman. Jurnal Kesehatan Andalas.

Ongun, P., \& Intepeler, S. S. (2017). Operating room professionals' attitudes towards patient safety and the influencing factors. Pakistan Journal of Medical Sciences. https://doi.org/10.12669/pjms.335.13615

Pugel, A. E., Simianu, V. V., Flum, D. R., \& Patchen Dellinger, E. (2015). Use of the surgical safety checklist to improve communication and reduce complications. Journal of Infection and Public Health. https://doi.org/10.1016/j.jiph.2015.01.001

Ragusa, P. S., Bitterman, A., Auerbach, B., \& Healy, W. A. (2016). Effectiveness of surgical safety checklists in improving patient safety. Orthopedics. https://doi.org/10.3928/0147744720160301-02

Ramsay, G., Haynes, A. B., Lipsitz, S. R., 
Solsky, I., Leitch, J., Gawande, A. A., \&

Kumar, M. (2019). Reducing surgical mortality in Scotland by use of the WHO

Surgical Safety Checklist. British Journal of Surgery.

https://doi.org/10.1002/bjs.11151

Ratman, M. F., Tanuwidjaja, S., \& Kusmiati, M.

(2014). Pelaksanaan sistem keselamatan pasien ( patient safety ) di RSU Bhakti Asih Kota Tangerang Tahun 2014. Prosiding Pendidikan Dokter.

Russ, S. J., Rout, S., Caris, J., Moorthy, K., Mayer, E., Darzi, A., ... Vincent, C. (2014). The WHO surgical safety checklist: Survey of patients' views. BMJ Quality and Safety. https://doi.org/10.1136/bmjqs-2013-002772

Russ, S., Rout, S., Caris, J., Mansell, J., Davies, R., Mayer, E., ... Sevdalis, N. (2015). Measuring variation in use of the WHO surgical safety checklist in the operating room: A multicenter prospective crosssectional study. Journal of the American College of Surgeons. https://doi.org/10.1016/j.jamcollsurg.2014. 09.021

Sandrawati, J., Supriyanto, S., \& Nurul, D. T. (2013). REKOMENDASI UNTUK MENINGKATKAN KEPATUHAN PENERAPAN SURGICAL SAFETY CHECKLIST DI KAMAR BEDAH (Recommendations to Improve the Implementation Compliance of Surgical Safety Checklist in Surgery Rooms). Buletin Penelitian Sistem Kesehatan.

Stahel, P. F., \& Mauffrey, C. (2014). Patient safety in surgery. In Patient Safety in Surgery. https://doi.org/10.1007/978-14471-4369-7

The Joint Commission. (2016). Hospital National Patient Safety Goals. In Hospital National Patient Safety Goals 2016. https://doi.org/10.1136/bjophthalmol-2014305816

Treadwell, J. R., Lucas, S., \& Tsou, A. Y. (2014). Surgical checklists: A systematic review of impacts and implementation. BMJ Quality and Safety. https://doi.org/10.1136/bmjqs-2012-001797

Van Klei, W. A., Hoff, R. G., Van Aarnhem, E. E. H. L., Simmermacher, R. K. J., Regli, L. P. E., Kappen, T. H., ... Peelen, L. M. (2012). Effects of the introduction of the WHO "surgical safety checklist" on inhospital mortality: A cohort study. Annals of Surgery.
https://doi.org/10.1097/SLA.0b013e318237

$79 \mathrm{ae}$

Vivekanantham, S., Ravindran, R. P., Shanmugarajah, K., Maruthappu, M., \& Shalhoub, J. (2014). Surgical safety checklists in developing countries. International Journal of Surgery. https://doi.org/10.1016/j.ijsu.2013.10.016 World Health Organization (WHO). (2018). WHO 10 facts on patient safety. 